\title{
Sexually Immature
}

National Cancer Institute

\section{Source}

National Cancer Institute. Sexually Immature. NCI Thesaurus. Code C158352.

The life stage before which the organism is capable of reproduction. 